\title{
How to create individual educational trajectories in the informational educational environment
}

\author{
T.O. Krasnopeeva ${ }^{1 *}$, A.I. Shevchenko ${ }^{2}$, and I.V. Romanova ${ }^{3}$ \\ ${ }^{1}$ Tomsk State University, Tomsk, Russia \\ ${ }^{2}$ Vyatka State University, Kirov, Russia \\ ${ }^{3}$ Vyatka State University, Kirov, Russia
}

\begin{abstract}
The article considers the issues of designing individual educational trajectories for University students in the informational educational environment from the perspective of personal-oriented, environmental and professionally oriented approaches. The leading research methods are comparative statistical analysis and modeling, the first of which helps to analyze quantitative data that reflect parameters that are important for students' academic performance and progress in the information educational environment, while the latter allows to model linguistic profiles designed for the individual educational trajectories. The informational educational environment as a unit of the educational space of the discipline "Foreign language" is a set of the following components: resource, informational components and socio-methodological, subjectoperational and didactic-methodological sub-components, as well as subject-activity and procedural components.
\end{abstract}

\section{A problem statement}

The current educational situation, including the globalization and the use of informational resources in the system of education, makes it obvious that in the field of education, which is undergoing a period of transformation, students are needed to possess not only academic knowledge, but also skills of a professional oriented and informational character for their future professional activities. A special role here is played by individual educational trajectories, which are "a type of training created by the student in cooperation with the teacher and focused on the needs that are formed in real time, as well as taking into accounts the personal characteristics of the student" [1].

The design of individual educational trajectories is carried out in the informational educational environment, which is one of the components of the educational space of the discipline "Foreign language". However, the analysis of researches in the field of environmental approach (L.S. Vygotsky, V.I. Ginetsinsky, V.A. Kozyrev, E.K. Samerkhanova, M. Heidegger and others) showed that when describing the modern educational system, researchers use the concepts of educational space or educational environment, not always clearly dividing them. This makes it difficult, firstly, to select the content of the components of the educational environment, and secondly, to organize the

*Corresponding author: ipcs-profped@yandex.ru 
components of this environment aimed at designing individual educational trajectories for students. In this regard, we discuss two interrelated questions: a) what organizational parameters affect students ' academic performance while learning foreign languages in the informational educational environment, and b) what individual educational trajectories should be that allow students to develop their communicative competence in the professionally oriented informational educational environment. These questions are the tasks that we plan to solve in this article.

\subsection{The objective of the work}

In the course of analysis of philosophical (A.N. Whitehead, M. Heidegger, A.A. Gritsanov, G.G. Kirilenko, I.T. Frolov, etc.) and psychological and pedagogical literature (L.S. Vygotsky, V.I. Ginetsinsky, V.E. Kagan, V.A. Kozyrev, A.V. Khutorskoy, etc.), we came to the conclusion that the educational environment can be considered as a unit of educational space, which has all the features and characteristics of the educational space [2, p. 199]. In the center of our research is the professionally oriented informational educational space of the discipline "Foreign language", which is, firstly, an integral, multicomponent system of the foreign language educational process consisting of resource, informational, subject-activity and procedural components [3, p. 376], the content of which is specially selected and organized to achieve the learning goal. Secondly, the units of this space are professionally oriented informational educational environments where individual educational trajectories of students are designed.

In the structure of the professionally oriented informational educational environment, we have identified a resource component represented by a set of informational tools (traditional: student's books; multimedia: Internet resources and Internet technologies) [4]. It is used to fill the content of subsequent components of the environment. Thus, the informational component is filled with professionally oriented information, which, in accordance with its content, is included in the a) socio-methodological subcomponent that determines the conditions and factors of organizing the foreign-language educational process; b) subject-operational, representing the information that the teacher and students work with; and c) didactic-methodical, containing techniques and teaching tools that help participants in the educational process to transmit and receive information.

\section{Materials and the results of the research}

The interactions themselves are carried out in the procedural component, where the teacher and students, as representatives of the subject-activity component, accumulate the received information and exchange it during the educational process [5, p. 73]. Since the presented educational environment is intended for individual educational trajectories, it should create optimal conditions for achieving the mentioned result. Thus, the teacher must specifically select and organize the content of the environment, based on the fact that it should be socially and methodologically determined by external and internal factors of the educational process, subject-operationally filled and didactically and methodically equipped to design individual educational trajectories for students in order to achieve the learning goal.

In this regard, the external factors include the social order of society, reflected in the Federal State Educational Standard and implemented in the work program, as well as a set of personal-oriented, environmental and professionally-oriented approaches [6, p. 138]. The internal factors characterize the level of the development of such personal and subjective characteristics of students as erudition, professional tact and professional ethics, interest in 
their profession, etc., and the level of their speech skills, educational skills and skills of professional activities.

The personal-oriented approach (B.G. Ananyev, L.S. Vygotsky, I.A. Zimnyaya, A.A. Leontiev, A.N. Leontiev, S.L. Rubinstein, A.V. Khutorskoy, and others) involves taking into account the personal and subjective characteristics of students [7] that are important for their future professional activities when selecting the content of the subject-operational subcomponent of the professional oriented informational educational environment. It includes professionally oriented materials that reflects the needs, motives, value orientations, interests and inclinations of the students, as well as personal and professional qualities as empathy, tolerance, professional ethics, and so on [8, p. 67].

The environmental approach (A.A. Bogdanov, I.L. BIM, L.S. Vygotsky, A.K. Gastev, Yu.V. Gromyko, V.V. Davydova, A.L. Denisova, S.D. Deryabo, Yu.S. Manuilov, Yu.S. Pesotsky, S.T. Shatsky, F.I. Schmidt, V.A. Yasvin, etc.) determines the organization of the educational process of the discipline in a professionally oriented informational educational environment, which is an integral multi-component system [9, p. 85] for achieving the learning goal. Such environment should be socially-methodologically determined, subjectoperationally filled and didactically-methodically equipped in such a way that the teacher and the students can interact in it to design individual educational trajectories [10].

The personal-oriented and environmental approaches determine the purpose and organization of the educational process in General, but the professionally-oriented approach (B.S. Gershunsky, E.V. Denisova, A.A. Derkach, I.A. Winter, O.Y. Ivanova, A.K. Markova, D.L. Matukhin, R.P. Millrood, P. Obraztsov, N.T. Sergeev, V.V. Serikov, A.V. Khutorskoy, J.A. Van Ek, etc.) allows to specify the content of the components of professionally oriented informational educational environment created for designing individual educational trajectories of foreign language. Thus, this approach requires taking into account the needs of students in learning foreign languages, dictated by the specifics of the future professional activity of students $[11, \mathrm{p}$. 6]. Therefore, the content of the subjectoperational subcomponent of the environment is carried out by selecting professionallyoriented material, where students firstly update existing knowledge, and then work with the new information in order to understand, compare, analyze and generalize this information. Taking into account the external and the internal factors allowed us to identify the principles of selection and organization of the informational educational environment. These principles are: a) professional orientation; b) information fullness; c) personal and subjective individualization; d) problem-informational sufficiency of educational material.

The principle of professional orientation involves taking into account the future profession of the student when selecting the text material and the tools of working with it in order to form an interest, professional qualities and value attitude to future professional activity [12, p. 69]. The principle of informational fullness encourages the teacher to select professionally oriented content from the educational space that is necessary and sufficient, as well as personally significant for students. The principle of personal and subjective individualization is intended to organize professionally-oriented foreign language communication for students in the problem situations presented in the selected texts, taking into account the interests, motives, personal qualities such as tolerance, ethical standards, professional tact, and inclinations of students preparing to solve educational and speech tasks of a professionally-oriented character. The principle of problem-informational sufficiency of educational material is closely related to the principle of information fullness and encourages the teacher to organize the modelling of individual educational trajectories in such a way that the selected information is quantitatively sufficient, has a problem character and is aimed at joint training of all types of speech activity in the sequence from receptive to productive. 
In order to correlate the selected principles with the learning conditions and subjectcontent equipment of the discipline "Foreign language", firstly, we organized a survey of the teaching staff and students. Thus, within the framework of personally-oriented and professionally-oriented approaches, the survey reveals the level of psychological, social, linguistic and educational readiness of students to implement professionally-oriented interaction in the context of distance learning. Secondly, the use of the Fisher criterion, which is related to the environmental approach, allows us to determine the validity of the desired result without error when interpreting the survey data, based on the number of respondents more than 50, but less than 100. Thirdly, the analysis of students' sociolinguistic profiles and their correlation with the CEFR in the framework of a professionally-oriented approach helps to determine the ability of students to engage in professional interaction with the teacher and each other in accordance with the levels of proficiency in reading, listening, speaking and writing as a means of foreign language communication.

The experiment was conducted in the second semester of 2019-2020 academic years on the basis of Tomsk state University and Vyatka state University. A total number of students participated in the experiment is 75 (35 students from Tomsk State University +40 students from Vyatka state University), including 35 1st-year students from Tomsk state University and 40 1st-year students from Vyatka state University.

The experiment aimed to develop an algorithm for designing individual foreign language educational trajectories in the professional oriented informational educational environment by identifying students' sociolinguistic profiles based on their social experience, taking into account the correct organization of the informational educational environment, answering the following questions:

a) what organizational parameters affect students ' academic performance while learning foreign languages in the informational educational environment;

b) what individual educational trajectories should be that allow students to develop their communicative competence in the professionally oriented informational educational environment.

The experiment was conducted by the method of survey of students. In table 1, one can see what parameters were decisive for the organization of the educational process in two universities, as well as the percentage of positive and negative responses to questions based on the number of students more than 50, but less than 100 (see table 1). All respondents from two universities are taken for $100 \%$ in this table and their ratio is distributed relative to their answers. The comparison is made in order to determine the organizational aspects that need to be improved in the future when designing and improving individual trajectories. It should be noted that students, as subjects of the professional oriented informational educational environment, generally want and have a certain set of qualities to participate in the interactions in the conditions of distance learning, but they experience difficulties related to motivational, educational, cognitive and technical aspects. 
Table 1. Organizational parameters for teaching Tomsk State University and Vyatka State University students.

\begin{tabular}{|c|c|c|c|c|c|}
\hline Question & $\begin{array}{l}\text { Organization } \\
\text { al parameter } \\
\text { identified by } \\
\text { the question }\end{array}$ & $\begin{array}{l}\text { Students' } \\
\text { answers TSU } \\
(\%) \text {, answer } \\
\text { "yes" }\end{array}$ & $\begin{array}{l}\text { Students' } \\
\text { answers } \\
\text { TSU (\%), } \\
\text { answer } \\
\text { "no" }\end{array}$ & $\begin{array}{l}\text { Students' } \\
\text { answers } \\
\text { VSU (\%), } \\
\text { answer } \\
\text { "yes" }\end{array}$ & $\begin{array}{l}\text { Students' } \\
\text { answers } \\
\text { TSU (\%), } \\
\text { answer } \\
\text { "no" }\end{array}$ \\
\hline $\begin{array}{l}\text { Are there enough } \\
\text { training materials } \\
\text { offered by teachers } \\
\text { to master the } \\
\text { discipline? }\end{array}$ & Sufficiency & $54 \%$ & $46 \%$ & $52 \%$ & $48 \%$ \\
\hline $\begin{array}{l}\text { Does the level of } \\
\text { complexity in the } \\
\text { tasks correspond to } \\
\text { the content of the } \\
\text { discipline? }\end{array}$ & Complexity & $29 \%$ & $71 \%$ & $25 \%$ & $75 \%$ \\
\hline $\begin{array}{lr}\text { Were } & \text { you } \\
\text { interested in } \\
\text { completing the } \\
\text { suggested tasks? }\end{array}$ & Interest & $49 \%$ & $51 \%$ & $48 \%$ & $52 \%$ \\
\hline $\begin{array}{l}\text { Did you manage to } \\
\text { learn more } \\
\text { information about } \\
\text { the discipline } \\
\text { during distance } \\
\text { learning? }\end{array}$ & Usefulness & $40 \%$ & $60 \%$ & $33 \%$ & $67 \%$ \\
\hline $\begin{array}{l}\text { Did you use } \\
\text { additional } \\
\text { materials to } \\
\text { expand the } \\
\text { information on the } \\
\text { proposed topic? }\end{array}$ & & $80 \%$ & $20 \%$ & $75 \%$ & $25 \%$ \\
\hline $\begin{array}{l}\text { Did the teacher } \\
\text { give feedback in } \\
\text { time? } \\
\text { Were deadlines set } \\
\text { for completing the } \\
\text { task? }\end{array}$ & Involvement & $20 \%$ & $80 \%$ & $18 \%$ & $82 \%$ \\
\hline $\begin{array}{l}\text { Did you spend } \\
\text { more time studying } \\
\text { the suggested } \\
\text { information? }\end{array}$ & & $77 \%$ & $23 \%$ & $78 \%$ & $24 \%$ \\
\hline
\end{tabular}

The survey data allow us to identify that the following parameters are important for students from the point of view of the organization of training and directly affect their academic performance and, as a result, their progress in learning. Thus, the table shows that the sufficiency and interest of materials reflects approximately equal quantitative indicators in two universities, i.e. the amount of information offered for study, as well as consistency in the development and implementation of materials, which indicates a high readiness of the teaching staff to work in the informational educational environment.

Complexity, usefulness, and involvement are parameters that show the level of psychological and educational training of both students and teachers. Whether they are able, firstly, to predict and plan their educational activities, secondly, to find the necessary information and independently structure it, and thirdly, to express their thoughts with 
sufficient completeness and accuracy in accordance with educational and speech tasks, interacting with each other and with the teacher. These indicators reflect the problematic aspect in the organization of materials, in other words, whether the information offered to students contains answers to the questions or only aspects with the help of which students should independently draw conclusions. Thus, if sufficiency and interest are organized correctly in terms of individual indicators of each student, then the big question is the significant difference in indicators of complexity, usefulness and involvement. That's why, the data reflect the answer to the first question "What organizational parameters affect students' academic performance when passing the discipline "Foreign language" in the informational educational environment?", identifying those organizational aspects that need to be improved in two universities, making the informational educational environment equally effective for all students.

The hypothesis of this study is that the effectiveness of organizational aspects of complexity, usefulness, and involvement, which represent their own latent characteristics for each student and, in this regard, showed a significant difference in the survey, can be improved by individualizing the learning process. In order to individualize learning, we propose to identify sociolinguistic profiles of students and correlate them with the levels of foreign language proficiency, thereby revealing the average correlation of the linguistic picture of students with the trajectories designed by the teacher, which would allow us to correlate the material suitable for each of the students' needs, abilities and motives.

In order to answer the second question, namely: "what individual educational trajectories should be that allow students to develop their communicative competence in the professionally oriented informational educational environment", let's compare the influence of the social and linguistic factors with the responses of students. Thus, social factors include age, environment, goals, motives, desires, and attitudes. To determine the degree of influence of social factors on students' responses, we used an analysis of variance, where "1" - Yes, "0" - No. Table 2 shows the total sum of students ' responses to each question (see table 2).

Table 2. Social and linguistic factors.

\begin{tabular}{|l|l|l|l|l|}
\hline Questions & \multicolumn{3}{l}{$\begin{array}{l}\text { Students' answers TSU } \\
\text { (35 students) }\end{array}$} & \multicolumn{2}{l|}{$\begin{array}{l}\text { Students' answers VSU (40 } \\
\text { students) }\end{array}$} \\
\cline { 2 - 5 } & $\mathbf{1}$ & $\mathbf{0}$ & $\mathbf{1}$ & $\mathbf{0}$ \\
\hline How old are you? (18-20) & 28 & 7 & 34 & 6 \\
\hline $\begin{array}{l}\text { Do your parents have a higher } \\
\text { education? }\end{array}$ & 19 & 16 & 22 & 18 \\
\hline $\begin{array}{l}\text { Your family's income ( }>40 \text { thousand } \\
\text { rubles) }\end{array}$ & 20 & 15 & 24 & 16 \\
\hline $\begin{array}{l}\text { When you were a child, did you have } \\
\text { an access to gadgets, the Internet }\end{array}$ & 18 & 17 & 25 & 15 \\
\hline Do you have a full family? & 21 & 14 & 26 & 14 \\
\hline Do you have any brothers or sisters? & 15 & 20 & 18 & 22 \\
\hline Do your parents work? & 32 & 3 & 36 & 4 \\
\hline
\end{tabular}

To check the validity of the presented data, we will conduct a variance analysis of social factors that can affect the level of foreign language proficiency of students. The presented data were analyzed by using the Fischer criterion. The F-test in the analysis of variance determines whether the average values of several independent samples differ significantly. The result is significant if Fstat.>Fcrit., i.e. if the value of the indicator increases for the majority of subjects, this shift is called Fstat., and shifts in the opposite direction will be considered as Fcrit. In other words, when the level of statistical significance P- value $<0,05$, 
then the Fisher criterion is significant, and the influence of the studied factor can be considered proven.

According to the Fischer criterion, it is obvious that the sum of deviations SS $(3111,001)$, the number of degrees of freedom df (14), and the variance MS - 430,268 and 480.5 contain data on the initial values for the factor between the groups of students (TSU and VSU) and the final values. All this is necessary for calculations in the last three columns-the static value of the Fisher ratio (F static), the P-value, and the critical value of the Fisher ratio (F critical). Since the static value of the Fisher ratio (6.891119) is greater than the critical value (3.920124), we conclude with a $95 \%$ probability that the influence of social factors on the responses of students in the survey can be considered non-random. In confirmation of this, the intersection of the row "between students" and the column "Pvalue" is 0.0243137254901961 , which is less than $<0.05$. Consequently, the social factors such as age, environment, goals, motives, desires, and attitudes subjectively affect the learning process and the teaching of students and can, on the one hand, contribute to a more successful study of the discipline, and on the other hand, negatively affect the ability of students to accurately, fully, and deeply reveal the essence of the problem.

This allows us to conclude that, from a subjective point of view, the identified parameters let us compare the practice of two universities, thereby enabling teachers to work with specific organizational aspects (see table 1) for further design of individual educational trajectories, taking into account the analyzed data.

To answer the second question "what individual educational trajectories should be that allow students to effectively improve their communicative competence in remote work as part of foreign language training?", it seems necessary to find out not only how to work with students, but also what the linguistic profile of each of them is. To do this, we use the CEFR descriptors. So, analyzing the audience of students represented in the experiment, we can conditionally divide them into groups that could help determine the linguistic profile of each of the students [13].

Table 3. Sociolinguistic profiles of students.

\begin{tabular}{|c|c|c|}
\hline \multicolumn{3}{|c|}{ Sociolinguistic Profile Descriptors } \\
\hline $\begin{array}{l}\text { A person speaking more than one } \\
\text { language who is old enough to } \\
\text { study foreign languages; grew up } \\
\text { in a non-full, non-educated and } \\
\text { poor family with non-working } \\
\text { parents; being a child had no } \\
\text { access to the gadgets which could } \\
\text { reveal new forms of } \\
\text { communication and languages to } \\
\text { develop competence; had no } \\
\text { brothers and /or sisters who could } \\
\text { help develop communicative skills }\end{array}$ & $\begin{array}{l}\text { A person speaking more than } \\
\text { one language who is in the age } \\
\text { between } 17 \text { and } 25 \text {; grew up in } \\
\text { the average nuclear family } \\
\text { with one or more children; } \\
\text { family income is about or } \\
\text { more than } 500 \text { euros }\end{array}$ & $\begin{array}{l}\text { A person speaking more } \\
\text { than two languages who is } \\
\text { young enough to study } \\
\text { foreign languages; grew up } \\
\text { in the full, educated and } \\
\text { rich family with working } \\
\text { parents; being a child had } \\
\text { access to the gadgets which } \\
\text { could reveal new forms of } \\
\text { communication and } \\
\text { languages to develop } \\
\text { competence; had brothers } \\
\text { and /or sisters who were } \\
\text { able to help develop } \\
\text { communicative skills. }\end{array}$ \\
\hline \multicolumn{3}{|c|}{ Suggested correlation with organizational aspects of learning } \\
\hline $\begin{array}{l}\text { Sufficient material - a small } \\
\text { volume is required } \\
\text { The complexity of the material is } \\
\text { low } \\
\text { The interest of the material is high } \\
\text { The usefulness of the material is } \\
\text { high }\end{array}$ & $\begin{array}{l}\text { The sufficiency of the material } \\
\text { - the average volume } \\
\text { The complexity of the material } \\
\text { is average } \\
\text { The interest of the material is } \\
\text { high } \\
\text { The usefulness is high }\end{array}$ & $\begin{array}{l}\text { The sufficiency of the } \\
\text { material - requires a large } \\
\text { amount of } \\
\text { The complexity of the } \\
\text { material is high } \\
\text { The interest of the material } \\
\text { is high }\end{array}$ \\
\hline
\end{tabular}




\begin{tabular}{|c|c|c|c|c|c|}
\hline \multicolumn{2}{|c|}{$\begin{array}{l}\text { Student involvement is usually low } \\
\text { or medium }\end{array}$} & \multicolumn{2}{|c|}{$\begin{array}{l}\text { The involvement - medium or } \\
\text { high }\end{array}$} & \multicolumn{2}{|c|}{$\begin{array}{l}\text { The usefulness of the } \\
\text { material is high } \\
\text { The involvement of the } \\
\text { student - usually high }\end{array}$} \\
\hline \multicolumn{6}{|c|}{ Predicted CEFR Communicative Competence Level } \\
\hline$\overline{A 1}$ & A2 & B1 & B2 & C1 & $\mathrm{C2}$ \\
\hline $\begin{array}{l}\text { Can recognise } \\
\text { internationalism } \\
\text { s and words } \\
\text { common to } \\
\text { different } \\
\text { languages; - } \\
\text { identify the } \\
\text { probable } \\
\text { message of a } \\
\text { short, simple, } \\
\text { written text; - } \\
\text { follow in } \\
\text { outline short, } \\
\text { simple social } \\
\text { exchanges } \\
\text { conducted very } \\
\text { slowly and } \\
\text { clearly in } \\
\text { his/her } \\
\text { presence; - } \\
\text { deduce what } \\
\text { people are } \\
\text { trying to say } \\
\text { directly to } \\
\text { him/her, } \\
\text { provided they } \\
\text { speak very } \\
\text { slowly and } \\
\text { clearly }\end{array}$ & $\begin{array}{l}\text { Can understand } \\
\text { short, clearly } \\
\text { articulated } \\
\text { spoken } \\
\text { announcements } \\
\text { by piecing } \\
\text { together what } \\
\text { he/she } \\
\text { understands } \\
\text { from the } \\
\text { available } \\
\text { versions in } \\
\text { different } \\
\text { languages. Can } \\
\text { understand } \\
\text { short, clearly } \\
\text { written } \\
\text { messages. Can } \\
\text { use simple } \\
\text { warnings, } \\
\text { instructions and } \\
\text { product } \\
\text { information to } \\
\text { find relevant } \\
\text { information. }\end{array}$ & $\begin{array}{l}\text { Can use what } \\
\text { he/she has } \\
\text { understood in } \\
\text { one language } \\
\text { to understand } \\
\text { the topic and } \\
\text { main message } \\
\text { of a text in } \\
\text { another } \\
\text { language. Can } \\
\text { use parallel } \\
\text { translations of } \\
\text { texts to } \\
\text { develop } \\
\text { comprehensio } \\
\text { n in different } \\
\text { languages. } \\
\text { Can extract } \\
\text { information. } \\
\text { Can recognize } \\
\text { similarities } \\
\text { and contrasts } \\
\text { between } \\
\text { concepts }\end{array}$ & $\begin{array}{l}\text { Can use } \\
\text { his/her } \\
\text { knowledge } \\
\text { of } \\
\text { contrasting } \\
\text { genre } \\
\text { conventions } \\
\text { and textual } \\
\text { pattern in } \\
\text { languages in } \\
\text { his/her } \\
\text { repertoire in } \\
\text { order to } \\
\text { support } \\
\text { comprehensi } \\
\text { on. }\end{array}$ & $\begin{array}{l}\text { Can } \\
\text { participate } \\
\text { effectively in } \\
\text { a conversation } \\
\text { in two or more } \\
\text { languages, } \\
\text { adjusting to } \\
\text { the changes of } \\
\text { language and } \\
\text { catering to the } \\
\text { needs and } \\
\text { linguistic } \\
\text { skills of the } \\
\text { interlocutors. } \\
\text { Can use and } \\
\text { explain } \\
\text { specialized } \\
\text { terminology. } \\
\text { Can respond } \\
\text { spontaneously } \\
\text { and flexibly in } \\
\text { the } \\
\text { appropriate } \\
\text { language. }\end{array}$ & $\begin{array}{l}\text { Can } \\
\text { interact in } \\
\text { a } \\
\text { multiling } \\
\text { ual } \\
\text { context } \\
\text { on } \\
\text { abstract } \\
\text { and } \\
\text { specialize } \\
\text { d topics } \\
\text { and if } \\
\text { necessary } \\
\text { explainin } \\
\text { g the } \\
\text { different } \\
\text { contributi } \\
\text { ons made. } \\
\text { Can } \\
\text { explore } \\
\text { similaritie } \\
\text { s and } \\
\text { difference } \\
\text { s between } \\
\text { metaphor } \\
\text { s and } \\
\text { other } \\
\text { figures of }\end{array}$ \\
\hline
\end{tabular}

Despite the fact that the table above is extremely approximate, however, in our opinion, it allows to differentiate the students not only according to their level of foreign language proficiency, but also the selection of material according to the subjective latent characteristics of students, reflecting their needs and motives not only as a subject of educational activity, but also as an individual with their own psychosocial and sociolinguistic characteristics. This differentiation has been studied for several decades within the framework of a personal-oriented approach by domestic (B.G. Ananyev, L.S. Vygotsky, I.A. Zimnaya, A.A. Leontiev, A.N. Leontiev, S.L. Rubinstein, A.V. Khutorskoy, etc.) and foreign scientists (Ritter \& Jaekel, Vogt, etc.).

In order to develop individual foreign language educational trajectories, you should follow the following algorithm of actions:

1. Formulate the purpose of training based on the Federal state educational standard, the motives and needs of the student in obtaining education, namely: a) examine private goals, objectives and required outcome of the training in accordance with local regulations of the foreign language teaching on the basis of which will be training; b) determine the rules for designing the individual foreign language educational trajectory in accordance with the form of education (the total number of hours of foreign language training, the fullness of the classroom and other recommendations for the organization of training, recorded by the organization); c) determine the volume of the individual foreign language educational 
trajectory according to the form of training (only as the main training program/only as an additional training program/combined); d) determine the acceptable ratio of the volume of the classroom load and the use of distance learning technologies; e) determine the degree and the volume of the need and sufficiency of implementing the individual foreign language educational trajectory; f) select the content of the individual foreign language educational trajectory, systematize it and group it based on the individual sociolinguistic profiles of the student.

2. Determine the content of the individual foreign language educational trajectory, identify the motives and needs of students using the following steps: a) conduct entrance testing of students in English. Check the test results of each student using the CEFR scale; b) adjust the work program based on the results according to the identified shortcomings in knowledge and focus on filling these shortcomings in the educational process; c) identify the motivation of students through specially designed didactic exercises and create / use ready-made leveling elective courses (if necessary), taking into account the individual characteristics of students. Deficiencies in knowledge are compensated by students as a result of performing additional exercises on the educational platform, in our case, Moodle. Thus, such factors as low pace and productivity in the educational process, insufficient speed of perception of the material are eliminated; d) allow the students to make their own choices in the implementation of the developed tasks in accordance with the skills; regulate only the minimum number of tasks performed and the deadline for their completion; e) monitor the progress of individual work in the form of creating educational content according to the algorithm we have proposed; f) organize final (if necessary, also include intermediate) testing and analyze data on individual characteristics of students.

3. Compare measurable indicators of the effectiveness of the individual trajectory of foreign language education based on psychometric data on the individual characteristics of students with: a) the goals, objectives and expected results set out in the Federal laws and regulations of the state educational standards; b) the goals, objectives and expected results of local acts of the organization; c) the CEFR (if necessary, through independent testing).

Thus, based on the different sociolinguistic experience of the student, it is possible to select individual tasks for each linguistic profile, taking into account which tasks are most necessary, thereby realizing the right of the student to individualize training, and, at the same time, without deviating significantly from the work program. This combination of a free and democratic style of teaching and, at the same time, compliance with the requirements of the Federal State educational standards gives great prospects for effective foreign language teaching.

We will use the principles listed above to fill the informational educational environment with the content that is necessary for designing individual educational trajectories. To this end, we will refer to the equipment that is part of the resource component of the educational environment, and also rank the training tools presented below according to the profiles highlighted in table 3.

Among the variety of learning tools at the present stage of education development, multimedia tools play a special role, since they "organize a special educational environment that contributes to the development of cognitive activity and creative abilities of students due to their content nature" [14, p. 12]. At the same time, due to the insufficient technical capabilities of a number of educational institutions and a small number of multimedia tools developed for a specific training area, the teacher attracts all available means, namely material and multimedia, to equip the informational educational environment. As for multimedia tools, in order to manage them in an orderly manner, it became necessary to choose an Internet platform (M.V. Arkhipova, D.K. Bartosh, P. Benson, S.J. Hoffman, etc.), with which they can be presented [15]. This is the Moodle Internet platform, as it is 
specially designed for educational purposes and is officially accepted in these educational institutions.

The leading material tools of equipment is the student's book, which includes various artistic, journalistic, popular science and educational texts in terms of volume and content, from which students receive information and language means for its transmission. In addition to the texts presented visually, the students' book contains texts for listening, presented using audio and video materials.

The next tools of equipping the informational educational environment are Internet resources as part of hotlist, treasure hunt, multimedia scrapbook, subject sampler, treasure hunt, webquest [16], kahoot [17, p. 3], presented on the basis of the Moodle Internet platform. They allow you to expand and deepen the information offered in the textbook by including additional text, audio, and video materials. Therefore, the information contained in these Internet resources should include a sufficient amount of professionally oriented material that the teacher and students will work with, interacting with each other. So, "hotlist "and" treasure hunt " are a list of sites selected by the teacher, where information is contained, including various statements and situations of everyday communication, which are foreign-language means of transmitting this information. These tools correspond to levels A1 and A2, as they contain direct answers to questions about the content of the information provided. In" multimedia scrapbook "and" subject sampler", the teacher uses various information presented in the form of texts, audio recordings or video clips. These tools correspond to levels B1 and B2, as they contain text, audio, video and multimedia materials after studying which students are asked questions of a discussing character. In order to give the educational process a professional orientation, we selected such Internet technologies as webquest, forums [18], and kahoot, which correspond to levels C1 and C2 and involves pair and group work of students. So, "webquest" involves the teacher organizing both group and individual work of students, which is aimed at extracting, understanding and comparing information presented in text, audio or video form. The teacher provides general information about the problem, and then highlights the subproblems that each group of students will discuss. During the discussion, students learn from each other all aspects of the problem and express their opinion.

The forum as an online learning technology is, on the one hand, an effective means of organizing independent work of students, where students get the information, comprehend it, and then choose those foreign-language lexical and grammatical tools that help to create written works. Kahoot, in contrast to the previous Internet technologies, where students and teachers interact while working with educational materials [19, p. 201], is designed by a teacher who compiles tests containing various professionally oriented information presented in text, audio and video formats. The rate of completion of tasks by students is regulated by introducing a time interval for each question. Students are automatically awarded points for correct answers. As you can see, kahoot allows the teacher to perform a controlling function and determine the level of professionally oriented information $[20, \mathrm{p}$. 41].

Thus, a set of material and multimedia tools based on the Moodle Internet platform, selected taking into account the principles of professional orientation; information saturation; personal and subjective individualization and problem-information fullness of educational material fills the components of the information educational environment to achieve the learning goal, which in our case is the design of individual educational trajectories. 


\section{Conclusions}

Summing up the solution of the tasks, we can say that the characteristic and analysis of the component content of the informational educational environment made it possible not only to design a model of this environment intended for creating individual educational trajectories, but also to fill such an environment with specific personal-oriented content. This was facilitated by the principles of professional orientation, informational fullness, personal and subjective individualization, as well as problem-information sufficiency of the educational material, identified taking into account the external and the internal factors that determine the process of foreign language education. Answering the first question "what organizational parameters affect students' academic performance in the course of "Foreign language" in the professional oriented informational environment", we identified such parameters as the sufficiency and complexity of materials, the interest and usefulness of the information offered, the involvement of participants in the educational process (teacher and students). These parameters are presented as quantitative indicators and reflect the organizational aspect in the distribution of the content of information and the sequence when it is presented. In other words, each parameter, on the one hand, shows the level of psychological readiness, and on the other hand, training of both students and teachers, i.e. their ability to a) predict and plan educational activities, b) extract the necessary information and independently structure it, c) express their thoughts with sufficient completeness and accuracy in accordance with educational and speech tasks, entering into different types of interactions (individual, pair, group).

As for the second question "what individual educational trajectories should be that allow students to effectively improve their communicative competence ", we analyzed the sociolinguistic profile of students using the CEFR descriptors, and concluded that it is possible to select individual tasks for each sociolinguistic profile, taking into account which tasks are of great importance for a particular student, by adding various Internet resources to the learning process, depending on the level of students ' training, without deviating from the work program. This combination of free distance learning and traditional learning styles provides great prospects for effective foreign language teaching.

\section{References}

1. S.K. Gural, T.O. Krasnopeeva, V.M. Smokotin, S.N. Sorokoumova, Goals, tasks, principles and content of individual foreign language educational trajectories based on the latent characteristics of the students, Language And Culture, 47, 179-196 (2019).

2. S.S. Kuklina, A.I. Shevchenko, The formation of intercultural competence in a professionally oriented information educational environment of the university, Language and Culture, 47, 197-216 (2019).

3. E.K. Samerkhanova, Humanistic bases of creation of uniform information and educational space of higher education institution in the conditions of development of information society. Bulletin of Minin University, 2, 375-381 (2013).

4. O.G. Bardina, S.G. Dolzhenko, E.A. Yurinova, Formation of foreign language communicative competence among students of non-philological training profiles through content-based active speaking technology, Bulletin of the Novosibirsk State Pedagogical University, 8 (4), 7-25 (2018).

5. S.S. Kuklina, A.I., Shevchenko How to make professionally oriented educational environment of intercultural and professionally oriented character, Lecture Notes in Networks and Systems, 131, 71-81(2020). 
6. N.V. Baryshnikov, V.L. Bernstein, Formation of professional communicative intercultural competence: generalization of experience, search for methodological solutions, Language and Culture, 43, 136-147 (2018).

7. A.V. Khutorskoy, Technology of designing key and subject competencies, Internetmagazine "Eidos" (2005).

8. A.V. Khutorskoy, Design technology for key and subject competencies. Innovations in a comprehensive school. Teaching methods, Collection of scientific works, 65-79 (2006).

9. S.K. Gural, O.A. Obdalova, Conceptual basis for developing an educational environment for teaching intercultural communication, Language and Culture, 4 (20), $83-96$ (2012).

10. V.I. Ginetsinsky, The problem of structuring the global educational space, M.: Pedagogy, 3, 10-15 (1997).

11. P.V. Sysoev, The system of teaching a foreign language on individual trajectories based on modern information and communication technologies, Foreign languages at school, 5, 2-11 (2014).

12. N.V. Popova, T.V. Ovsyannikova, Formation of intercultural communicative competence and mediator position among university students in a multicultural educational space, Innovations in Education, 6, 68-83 (2016).

13. T.O. Krasnopeeva, M.I. Gromov, Analysis of statistical methods on plurilinguistic quantitative data, IOP Conf. Series: Journal of Physics (2020).

14. D.K. Bartosh, Modern educational trends in multimedia teaching of foreign languages, University Herald, 6, 2-14 (2011).

15. Brett Best, Simone C.O. Conceição, Transactional distance dialogic interactions and student satisfaction in a multi-institutional blended learning environment, European Journal of Open, Distance and E-Learning, 20 (1), 139-153 (2017).

16. N. Magen-Nagar, M. Shonfeld, Attitudes, openness to multiculturalism, and integration of online collaborative learning, Educational Technology \& Society, 21 (3), 1-11 (2018).

17. P. Chanpet, K. Chomsuwan, E. Murphy, Online project-based and formative assessment, Technology, Knowledge and Learning, 1-21 (2018).

18. E.V. Kostina, Model of mixed learning and its use in teaching foreign languages, Proceedings of higher educational institutions. Ser. Humanities, 1 (2), 141-144 (2015).

19. C. de Runze, S. Faiz, A.A. Cherif, Smart learning environment: Teacher's role in assessing classroom attention. Research in Learning Technology, 27, 56-67 (2019).

20. R.V. Mayer, Research of didactic systems with use of methods of computer modeling, Psychology, sociology and pedagogy, 7 (34), 37-42 (2014). 